
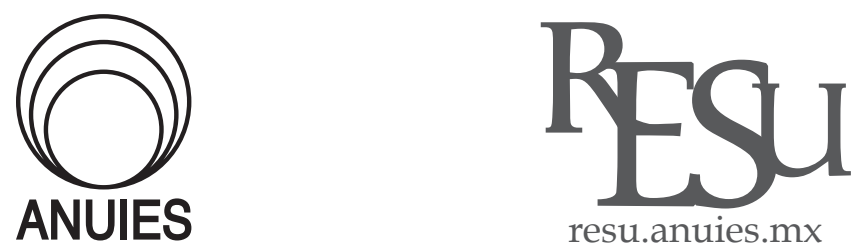



ARTí́CULO

\title{
La Educación del Futuro: creencias del alumnado
}

\section{Education of the Future: thinking of students}

\section{Sara Conde Vélez* y Ángel Boza Carreño**}

* Departamento de Educación. Universidad de Huelva (España). Correo electrónico: sara.conde@dedu.uhu.es

Recibido el 04 de noviembre del 2017; aceptado el 08 de febrero del 2019.

\section{Resumen}

Este artículo presenta un estudio cuyo objetivo es establecer las creencias del alumnado sobre la educación del futuro. La muestra contiene 431 alumnos de diferentes titulaciones de la Universidad de Huelva (España) y el instrumento de recogida de datos es una escala tipo Likert elaborada para ello. Los resultados obtenidos permiten validar la escala mediante análisis de consistencia interna, juicio de expertos y análisis factorial, describir las creencias de los alumnos sobre la educación del futuro y probar un modelo de relaciones. Estos resultados revelan la metodología didáctica como verdadera fuente del nuevo modelo de educación futura.

Palabras clave: Educación del Futuro; Contexto tecnológico; Metodología docente de proyectos colaborativos; Profesor orientador socio-crítico; Alumno constructivo social. 


\begin{abstract}
This article presents a study whose objectives are to establish the students' beliefs about the education of the future. The sample is 431 Students on different degree courses at the University of Huelva (Spain) and the data collection instrument is a Likert type scale developed for this purpose. The results obtained allow us to validate the scale through internal consistency analysis, expert judgment and factorial analysis, to describe students' beliefs about future education and to test a relationship. The results reveal teaching methodology as the true source of the new model for future education.
\end{abstract}

Keywords: Future Education; Technological Context; Methodology of Collaborative Projects; Socio-critical Teacher; Social Constructive Student.

\title{
Introducción
}

$\mathrm{P}$ ara planificar el futuro es importante mirar hacia atrás, pero sobre todo imaginar un porvenir posible a partir de las coordenadas que nos ofrece el presente. El NMC Horizon Report (2017) sobre educación superior indica las seis tendencias que aceleran la adopción de nuevas tecnologías y que deberían acometerse en los próximos 5 años: cultura de innovación, aprendizaje profundo, cambios en la evaluación de los aprendizajes, rediseño de espacios de aprendizaje, aprendizaje híbrido y aprendizaje colaborativo.

La tecnología está conduciendo a cambios de gran alcance en el mundo educativo (Vázquez, 2015). La red, Internet y las nuevas tecnologías están revolucionando el orden que conocemos. En Internet podemos encontrar diversos recursos docentes. Las personas pueden elegir lo que quieren estudiar, cómo lo van a estudiar y cuándo. El aprendizaje no tiene por qué darse sólo dentro del aula, y esto incita a reflexionar sobre el papel que ejercerán los nuevos docentes. Desenrollar modelos heterogéneos y colaborativos, pasar de los libros a las "app", pasar de los campus a los móviles y a las tabletas, hace que se produzcan cambios en la docencia, la investigación, la organización y los recursos. Los cursos online que ofrecen multitud de certificaciones pueden hacer surgir una gran cantidad de nuevos titulados que nos hace pensar sobre cómo influirá en las cuestiones organizativas de las titulaciones académicas con modelos tradicionales.

El avance de la Web 2.0 ha transformado el rol del usuario de Internet. Los procesos de colaboración y participación, el aprendizaje personalizado, el aprendizaje activo, las experiencias compartidas, se han visto beneficiados del uso de 
las redes sociales (Pérez Alcalá, Ortiz \& Flores, 2015; Trujillo, Aznar \& Cáceres, 2015). Averiguaciones recientes apuntan que son bien apreciadas como parte del entorno de aprendizaje (Castaño, Maiz \& Garay, 2015). Realidad virtual, chatbots y aplicaciones inmersivas han agregado más funcionalidad y mayor potencial de aprendizaje (Adams, Cummins, Davis, Freeman, Hall, \& Ananthanarayanan, 2017). En realidad la tecnología por sí sola no puede cultivar una transformación de la educación; hacen falta mejores pedagogías y modelos de educación más inclusivos. No obstante, sí impacta el cómo se utiliza la tecnología. Herrera (2015) afirma que la tecnología y sus aportaciones van evolucionando y cambiando los campos del conocimiento de manera muy rápida, es aquí donde se puede valorar que la educación, como disciplina, está asumiendo nuevos retos y desafíos que merecen un estudio más detallado. En este sentido pensamos que el contexto tecnológico determina la metodología didáctica usada y los modelos de profesor y de estudiante.

Los cambios que se están produciendo afectan a todas las dimensiones y elementos del trabajo educativo, la forma en la que se entiende el curriculum, la enseñanza y los nuevos papeles de los docentes y estudiantes. Progresamos hacia un modelo educativo que, a partir de los aprendizajes instrumentales básicos, estará caracterizado por el trabajo por proyectos de carácter social, colaborativos, cooperativos y donde las escuelas o las universidades no serán el fuerte del conocimiento y el saber, sino el nódulo de conexión crítico, estructurador, personalizador y dotador de sentido de los aprendizajes permanentes, diversos y ubicuos que emanarán de la gran red comunitaria socio-tecnológica de aprendizajes (Riera, 2016).

De acuerdo con Hernández (2017), es importante detallar el papel transformador del docente y el alumno en el proceso de enseñanza-aprendizaje. Un buen docente ha de ser capaz de localizar, organizar, emplear y adaptar los distintos recursos a los distintos momentos de su acción; utilizar variedad de recursos, el Internet y materiales digitales; emplear en el aula momentos de trabajo individualizados, socializadores, cooperativos; debe ser capaz de identificar, orientar, apoyar, fomentar y promover en las comunidades el proceso de formación del alumnado (López, González \& León, 2015). Las herramientas tecnológicas tiene que ser utilizadas por los docentes de modo apropiado dando lugar a un uso correcto dentro del alumnado (Manrique, 2015).

Díaz, Cebrián \& Fuster (2016) ponen de relieve que los estudiantes durante los procesos de enseñanza aprendizaje afirman la relación existente entre las competencias en TIC y las estrategias de aprendizaje. También observaron que las variables personales y contextuales son elementos claves en dichos procesos. García \& Tejedor (2015) indican que los estudiantes universitarios que hacen uso de las тic en sus estrategias de aprendizaje tienen un mayor éxito académico fa- 
cilitándoles sus tareas. El alumnado con rendimiento alto considera las TIC como una herramienta que ayuda a mejorar la elaboración de sus trabajos, la organización de la actividad, el estudio, el trabajo cooperativo y la búsqueda de recursos. Las TIC parecen ser un factor clave de éxito académico.

Pero no siempre los alumnos tienen esas competencias tecnológicas. Liesa, Vázquez \& Lloret (2016) indicaron que muchos de los estudiantes que llegan a la universidad tienen debilidades importantes en el uso de las herramientas de Internet, a pesar de formar parte de la generación digital. La mayoría de los estudiantes conocen y usan frecuentemente el navegador, el correo electrónico, la mensajería instantánea y las redes sociales generalistas, pero desconocen el resto de herramientas de Internet. La participación de los estudiantes en la educación también está sufriendo cambios en relación a los modelos tradicionales. Se ha pasado de estudios presenciales a no presenciales dedicando horas de trabajo desde el propio domicilio, con extensión a una formación a lo largo de toda la vida y estudiantes que tomarán cursos de diversas instituciones, con diversas modalidades y estrategias (Vázquez, 2015). Hien, Chang \& Nguyet (2017) confirman que el blended learning está significativamente asociado con mayor rendimiento de aprendizaje de los estudiantes que la práctica tradicional de la clase.

Por todo ello, consideramos que nuestras ideas sobre la educación del futuro (Suárez, Pérez, Boza \& García, 2012) aún están vigentes y pretendemos ponerlas a prueba en este trabajo. Contexto tecnológico, metodología docente, profesores, alumnos, son las dimensiones que se van a valorar aquí desde la visión del alumnado. Para ello hemos elaborado una escala con que pretendemos conocer las creencias de los alumnos al respecto.

El estudio pretende como objetivo general confirmar la conexión entre el contexto tecnológico, la metodología usada y el rol del profesor y el estudiante desde la perspectiva de los alumnos. Concretamente los objetivos específicos que se plantean son los siguientes:

- Establecer las creencias del alumnado sobre la educación del futuro examinando las opiniones que éstos tienen sobre contexto tecnológico, metodología docente, profesores y alumnos.

- Confirmar la influencia del contexto tecnológico sobre la metodología didáctica usada y ésta sobre los roles del profesor y el estudiante, desde la perspectiva de los alumnos.

Amparado en los planteamientos precedentes, se somete a contraste empírico. Las hipótesis que se plantean son las siguientes: 
- Hipótesis 1 (H1): El contexto tecnológico determina la metodología usada.

- Hipótesis 2 (H2): La Pedagogía que se use pronostica el modelo de profesorado.

- Hipótesis 3 (H3): La Pedagogía que se use pronostica el modelo de estudiante.

El modelo explicativo a contrastar sería el que se representa en la figura 1:

Figura 1

Modelo explicativo a contrastar de Educación del Futuro

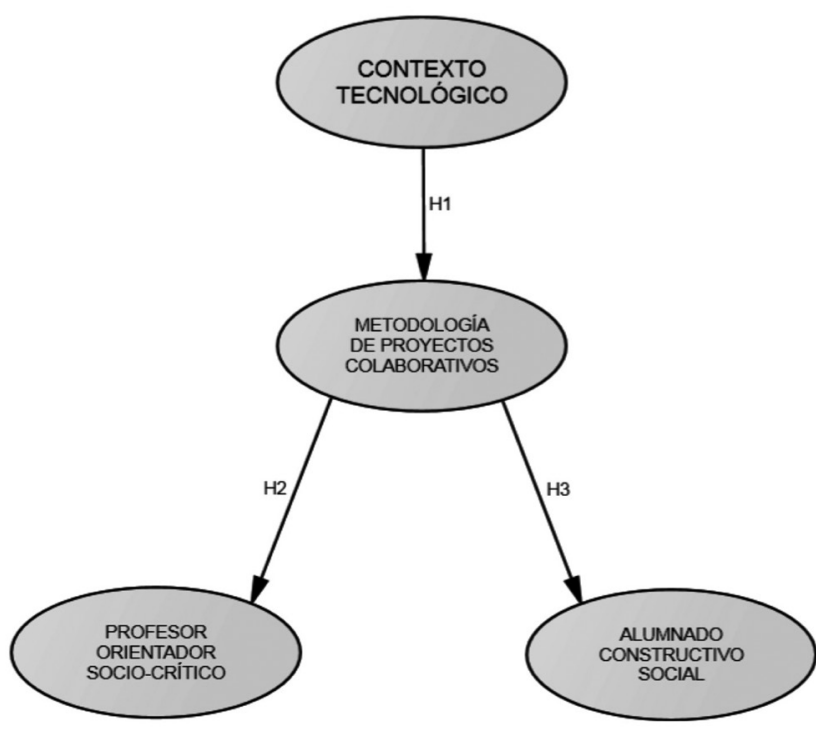

\section{Método}

Esta investigación sigue una metodología tipo encuesta, con un diseño transversal, y mediante una escala tipo Likert. Podemos calificar nuestra investigación como descriptiva y explicativa. La escala se recogió durante unas jornadas formativas transversales realizadas en la Universidad de Huelva. Fue entregada en papel a los alumnos el primer día de las jornadas y se recogió durante la dos semanas siguientes. 


\section{Muestra}

La población de estudio es el alumnado de la Universidad de Huelva. La muestra seleccionada es no probabilística, siguiendo los criterios de voluntariedad y cuota. Los alumnos han participado voluntariamente en la encuesta, pero hemos respetado la presencia de diferentes titulaciones (muestreo por cuotas) de la universidad. La muestra está constituida por 431 alumnos (35.7\% de hombres y $64.4 \%$ de mujeres), pertenecientes a diferentes titulaciones, con un rango de edad comprendido entre los 19 y 35 años ( $M=23.07$; DT $=2.77$ ). Tanto el tamaño de la muestra como el criterio de selección por cuotas de titulación garantizan de manera razonable, aunque no ideal, la representatividad de la muestra. Como datos tecnológicos personales, podemos decir que el 98.8\% tienen correo electrónico, el 96.5\% navega habitualmente en Internet, el 95.1\% usa plataformas de teleformación (Moodle o similar), el 93.3\% usa las redes sociales (Facebook, Tuenti, Twitter...), el 87\% usa aplicaciones en red (Gmail, Google Doc, Flick...), el 86.5\% ha publicado algo en Internet, el $86.3 \%$ usan chat y el $84.9 \%$ participa en foros, el $75.2 \%$ usa marcadores sociales, el $72.4 \%$ ha usado alguna herramienta Wiki, un 55.2\% dice tener blog, el 51.3\% comparten archivos de audio y el 50.8\% usa las tutorías virtuales, pero sólo un $31.3 \%$ tiene web personal o profesional.

\section{Instrumento}

Para la recogida de datos se elabora una escala, denominada 'La educación del futuro', a partir de nuestras propias ideas sobre la educación del futuro (Suárez-Rodríguez, Pérez-Sanz, Boza \& García-Valcárcel, 2012) y de las referencias citadas en la introducción. Esta escala pretende evaluar las creencias del alumnado sobre la educación del futuro y está compuesta por cuatro dimensiones: Contexto Tecnológico (12 ítems, Tabla 2), Metodología Docente Futura (11 ítems, Tabla 3), Profesores del Futuro (15 ítems, Tabla 4), Alumnos del Futuro (10 ítems, Tabla 5). La escala, de tipo Likert, con valores de 1 a 7 , se ha sometido a procesos de validación en cuanto a fiabilidad, mediante medidas de consistencia interna de Alfa de Cronbach; validez de contenido, mediante juicio de expertos; y validez de constructo, mediante análisis factorial.

El análisis de consistencia interna, Alfa de Cronbach, proporciona valores totales y de cada dimensión muy buenos (ver Tabla 1); pero también concluimos que sería deseable reducir la escala e identificar cuáles podrían ser los ítems a excluir (ver Tablas 2, 3, 4 y 5) . Como resultado de este análisis se eliminan los ítems CT1, CT10, CT11, MD7 y PF6. 
Tabla 1

Fiabilidad de la escala-Alfa de Cronbach

\begin{tabular}{lccc}
\hline & Alfa & Ítems menos consistentes & Alfa si los excluimos \\
\hline Contexto Tecnológico & .833 & CT1, CT10, CT11 & .850 \\
\hline Metodología Docente & .911 & MD7 & .918 \\
\hline Profesores & .915 & PF6 & .924 \\
\hline Alumnos & .897 & & .959 \\
\hline Escala & .971 & & \\
\hline
\end{tabular}

Tabla 2

Contexto Tecnológico Futuro (Alfa de Cronbach total= .833. Estadísticos total-elemento)

\begin{tabular}{|c|c|c|}
\hline & $\begin{array}{l}\text { Correlación elemento- } \\
\text { total corregida }\end{array}$ & $\begin{array}{c}\text { Alfa si se elimina el } \\
\text { elemento }\end{array}$ \\
\hline $\begin{array}{l}\text { CT1. La web } 2.0 \text { transformará el concepto y uso de } \\
\text { internet. }\end{array}$ & .395 & .829 \\
\hline $\begin{array}{l}\text { CT2. Creo que pronto internet será una web social } \\
\text { inteligente. }\end{array}$ & .492 & .820 \\
\hline $\begin{array}{l}\text { CT3. Internet puede llegar a ser el Gran Hermano } \\
\text { Virtual que todo lo ve. }\end{array}$ & .474 & .822 \\
\hline $\begin{array}{l}\text { CT4. Utilizaremos internet para hacer periodismo } \\
\text { ciudadano. }\end{array}$ & .529 & .818 \\
\hline CT5. Utilizaremos internet para divertirnos. & .563 & .815 \\
\hline $\begin{array}{l}\text { CT6. Utilizaremos internet para como plataforma } \\
\text { (sin instalar programas). }\end{array}$ & .547 & .816 \\
\hline $\begin{array}{l}\text { CT7. Utilizaremos internet para hacer } \\
\text { recomendaciones, opiniones, valoraciones. }\end{array}$ & .656 & .809 \\
\hline $\begin{array}{l}\text { CT8. Utilizaremos internet para crear en común, } \\
\text { remezclar y compartir. }\end{array}$ & .579 & .815 \\
\hline $\begin{array}{l}\text { CT9. Internet permitirá crear y ejercer una } \\
\text { inteligencia colectiva. }\end{array}$ & .648 & .809 \\
\hline $\begin{array}{l}\text { CT10. Las redes sociales seguirán siendo lo más } \\
\text { interesante de internet. }\end{array}$ & .171 & .849 \\
\hline $\begin{array}{l}\text { CT11. En internet cada vez habrá más infobasura, } \\
\text { basura semiótica. }\end{array}$ & .390 & .829 \\
\hline $\begin{array}{l}\text { CT12. Internet será más social, será la web de las } \\
\text { personas. }\end{array}$ & .587 & .813 \\
\hline
\end{tabular}

Tabla 3

Metodología Docente (Alfa de Cronbach= ,911. Estadísticos total-elemento)

\begin{tabular}{lcc}
\hline & $\begin{array}{c}\text { Correlación elemento- } \\
\text { total corregida }\end{array}$ & $\begin{array}{c}\text { Alfa si se elimina el } \\
\text { elemento }\end{array}$ \\
\hline $\begin{array}{l}\text { MD1. Queremos realizar proyectos reales de acción } \\
\text { o investigación en contextos reales. }\end{array}$ & .623 & .904 \\
\hline $\begin{array}{l}\text { MD2. Nos gustaría tener un prácticum profesional } \\
\text { integrado (formación + prácticas) a lo largo de toda } \\
\text { la carrera. }\end{array}$ & .722 & .899 \\
\hline $\begin{array}{l}\text { MD3. Creemos en la integración trabajo-estudio a lo } \\
\text { largo de toda la vida. }\end{array}$ & .696 & .901 \\
\hline
\end{tabular}

Continúa... 


\begin{tabular}{lcc}
\hline & $\begin{array}{c}\text { Correlación elemento- } \\
\text { total corregida }\end{array}$ & $\begin{array}{c}\text { Alfa si se elimina el } \\
\text { elemento }\end{array}$ \\
\hline $\begin{array}{l}\text { MD4. Nos gustaría aprender con recursos diversos: } \\
\text { textos, hipertextos, imágenes, sonidos.. }\end{array}$ & .728 & .899 \\
\hline $\begin{array}{l}\text { MD5. El aprendizaje será compartido, distribuido, } \\
\text { colaborativo. }\end{array}$ & .708 & .900 \\
\hline MD6. Los recursos educativos serán abiertos. & .726 & .899 \\
\hline $\begin{array}{l}\text { MD7. Usaremos las redes sociales como herramienta } \\
\text { de enseñanza y aprendizaje. }\end{array}$ & .417 & .918 \\
\hline MD8. Utilizaremos portafolios-wikis compartidos. & .521 & .910 \\
\hline $\begin{array}{l}\text { MD9. Los profesores tendrán blogs académico- } \\
\text { profesionales. }\end{array}$ & .715 & .900 \\
\hline $\begin{array}{l}\text { MD10. Utilizaremos objetos de aprendizaje } \\
\text { interactivos y coelaborados. }\end{array}$ & .777 & .997 \\
\hline $\begin{array}{l}\text { MD11. El profesor propiciará Entornos Personales } \\
\text { de Aprendizaje mediados. }\end{array}$ & .702 & .901 \\
\hline
\end{tabular}

Tabla 4

Profesor (Alfa de Cronbach= .915. Estadísticos total-elemento)

\begin{tabular}{|c|c|c|}
\hline & $\begin{array}{l}\text { Correlación elemento- } \\
\text { total corregida }\end{array}$ & $\begin{array}{c}\text { Alfa si se elimina el } \\
\text { elemento }\end{array}$ \\
\hline $\begin{array}{l}\text { PF1. El profesor debe ser competente tecnológica- } \\
\text { mente (audio, video, PC, internet) }\end{array}$ & .602 & .910 \\
\hline $\begin{array}{l}\text { PF2. El profesor debe ser competente didácticamen- } \\
\text { te con esos recursos. }\end{array}$ & .529 & .912 \\
\hline $\begin{array}{l}\text { PF3. Nos gustaría un profesor que participe en las } \\
\text { redes sociales. }\end{array}$ & .580 & .911 \\
\hline $\begin{array}{l}\text { PF4. Nos gustaría un profesor que elabore y suba } \\
\text { videos a la red. }\end{array}$ & .550 & .912 \\
\hline $\begin{array}{l}\text { PF5. Nos gustaría un profesor más comunicativo } \\
\text { con los alumnos. }\end{array}$ & .536 & .912 \\
\hline $\begin{array}{l}\text { PF6. Las tutorías on-line son más cómodas que la } \\
\text { tutoría presencial. }\end{array}$ & .315 & .924 \\
\hline $\begin{array}{l}\text { PF7. Ese profesor será un pensador, un observador } \\
\text { crítico de la realidad. }\end{array}$ & .694 & .907 \\
\hline $\begin{array}{l}\text { PF8. Ese profesor será un lector multidisciplinar } \\
\text { profundo. }\end{array}$ & .766 & .905 \\
\hline $\begin{array}{l}\text { PF9. Ese profesor será investigador multidisciplinar } \\
\text { que publica por interés científico. }\end{array}$ & .716 & .906 \\
\hline $\begin{array}{l}\text { PF10. Nos gustaría un docente generador de } \\
\text { conflicto cognitivo, divergente. }\end{array}$ & .673 & .908 \\
\hline $\begin{array}{l}\text { PF11. Ese profesor será un escritor de sus propias } \\
\text { reflexiones y experiencias. }\end{array}$ & .600 & .910 \\
\hline $\begin{array}{l}\text { PF12. Ese profesor será un gestor de contextos de } \\
\text { aprendizaje. }\end{array}$ & .737 & .906 \\
\hline $\begin{array}{l}\text { PF13. Ese profesor será un orientador de proyectos } \\
\text { personales de formación. }\end{array}$ & .740 & .906 \\
\hline $\begin{array}{l}\text { PF14. Ese profesor será un diseñador de objetos de } \\
\text { aprendizaje. }\end{array}$ & .690 & .907 \\
\hline $\begin{array}{l}\text { PF15. Ese profesor será un tutor, un asesor, un } \\
\text { orientador de personas. }\end{array}$ & .711 & .907 \\
\hline
\end{tabular}


Tabla 5

Alumno (Alfa de Cronbach= .897. Estadísticos total-elemento)

\begin{tabular}{lcc}
\hline & $\begin{array}{c}\text { Correlación elemento- } \\
\text { total corregida }\end{array}$ & $\begin{array}{c}\text { Alfa si se elimina el } \\
\text { elemento }\end{array}$ \\
\hline $\begin{array}{l}\text { AL1. Ejerceremos un rol más constructivo (debatir, } \\
\text { leer, investigar, criticar, escribir, compartir). }\end{array}$ & .581 & .891 \\
\hline $\begin{array}{l}\text { AL2. Nos organizaremos en comunidades virtuales } \\
\text { de trabajo. }\end{array}$ & .708 & .883 \\
\hline $\begin{array}{l}\text { AL3. Seremos expertos en el procesamiento rápido e } \\
\text { intuitivo de información digital multiformato (texto, } \\
\text { audio, imágenes, video). }\end{array}$ & .671 & .885 \\
\hline $\begin{array}{l}\text { AL4. Transformaremos la información en } \\
\text { producciones digitales. }\end{array}$ & .659 & .886 \\
\hline $\begin{array}{l}\text { AL5. Publicaremos en blogs individuales o } \\
\text { colaborativas. }\end{array}$ & .636 \\
\hline \begin{tabular}{l} 
AL6. Trabajaremos en redes multiprofesionales. \\
\hline $\begin{array}{l}\text { AL7. Seremos capaces de decidir y de intervenir } \\
\text { sobre la realidad en base a la información. }\end{array}$
\end{tabular} & .633 \\
\hline $\begin{array}{l}\text { AL8. Seremos muy creativos, fruto de la } \\
\text { hiperestimulación sensorial sufrida en nuestra vida. }\end{array}$ & .655 \\
\hline $\begin{array}{l}\text { AL9. Seremos co-productores de conocimiento. } \\
\begin{array}{l}\text { AL10. Este conocimiento será fundamentalmente } \\
\text { pragmático y muy contextualizado. }\end{array}\end{array}$ & .888 \\
\hline
\end{tabular}

La escala también ha sido sometida a juicio de expertos (6 profesores universitarios y 6 alumnos de posgrado en educación). Se les solicitó que evaluaran la pertinencia y la redacción de los ítems, obteniendo resultados satisfactorios en la mayoría de ellos. Tan sólo suscitaron algunas dudas de pertinencia relativas al ítem PF6, que finalmente optamos por excluir, y de redacción respecto de los ítems que empiezan por la expresión "Nos gustaría..." (PF3, PF4, PF5, PF6, MD2, MD4), que mantenemos a pesar de ello por ser afirmaciones relativas a preferencias de futuro de los alumnos sobre modelos de profesor y metodología docente.

Finalmente hemos sometido la escala a análisis factorial para determinar si cada una de las dimensiones constituye un único factor o componente (Boza y Conde, 2017 en revisión). El análisis es pertinente dados los altos índices кмо de las escalas, con valores comprendidos entre 0.831 y 0.946 , que permiten concluir la conveniencia del análisis factorial. Asimismo, la prueba de esfericidad de Bartlett, que evalúa la aplicabilidad del análisis factorial de todas las escalas, tiene un índice de significación $<0.001$, por lo que los análisis factoriales pueden aplicarse. Respecto del Contexto Tecnológico encontramos un factor principal y dos secundarios, que explican el $59.53 \%$ de la varianza, pero que también nos permiten concluir su unimensionalidad dado que todos los ítems saturan en el primer factor con excepción del ítem CT10, que debería ser excluido. Respecto de la Metodología Docente encontramos un factor principal (Metodología de Proyectos Colaborativos) y uno secundario, que explican el 66.09\% de la varian- 
za, aunque todos los ítems saturan alto en el primer factor, y permiten identificar MD7 como el ítem menos adecuado. Respecto del Profesorado encontramos un factor principal (Profesor Orientador Socio-Crítico) y dos secundarios, que explican el $67.39 \%$ de la varianza y nos permiten concluir su unimensionalidad dado que todos los ítems saturan en el primer factor con excepción del ítem PF6, que debería ser excluido. Respecto del Alumnado encontramos un factor principal (Alumno Constructivo-Social) y uno secundario, que explican el 68.24\% de la varianza, aunque todos los ítems saturan alto en el primer factor. Concluimos que tras la eliminación de los ítems citados todas las subescalas son unidimensionales.

\section{Resultados}

Presentaremos los resultados respondiendo a los dos objetivos de la investigación: a) Establecer las creencias del alumnado sobre la educación del futuro examinando las opiniones que éstos tienen sobre contexto tecnológico, metodología docente, profesores y alumnos; b) Confirmar la influencia del contexto tecnológico sobre la metodología didáctica usada y de ésta sobre los roles del profesor y el estudiante desde la perspectiva de los alumnos.

\section{Creencias del alumnado sobre la educación del futuro}

El alumnado caracteriza el Contexto Tecnológico Futuro (ver tabla 6), en este orden, por el uso de Internet para divertirse; crear en común, remezclar y compartir contenidos; hacer recomendaciones, opiniones y valoraciones sobre contenidos y productos; crear y ejercer inteligencia colectiva; hacer periodismo ciudadano. También coinciden que Internet será una web social inteligente y también una especie de "Gran Hermano Virtual", que usaremos cada vez aplicaciones en línea en vez de software propietario, y que Internet será cada vez más una web social.

Tabla 6

Creencias sobre contexto tecnológico futuro

\begin{tabular}{lccc}
\hline & N & Media & Desv. típ. \\
\hline $\begin{array}{l}\text { CT2. Creo que pronto internet será una web social } \\
\text { inteligente. }\end{array}$ & 430 & 5.14 & 1.55 \\
\hline $\begin{array}{l}\text { CT3. Internet puede llegar a ser el Gran Hermano } \\
\text { Virtual que todo lo ve. }\end{array}$ & 430 & 5.13 & 1.78 \\
\hline
\end{tabular}




\begin{tabular}{|c|c|c|c|}
\hline & $\mathbf{N}$ & Media & Desv. típ. \\
\hline $\begin{array}{l}\text { CT4. Utilizaremos internet para hacer periodismo } \\
\text { ciudadano. }\end{array}$ & 430 & 5.28 & 1.49 \\
\hline CT5. Utilizaremos internet para divertirnos. & 430 & 5.65 & 1.46 \\
\hline $\begin{array}{l}\text { CT6. Utilizaremos internet como plataforma (sin } \\
\text { instalar programas). }\end{array}$ & 430 & 5.00 & 1.65 \\
\hline $\begin{array}{l}\text { CT7. Utilizaremos internet para hacer } \\
\text { recomendaciones, opiniones, valoraciones. }\end{array}$ & 430 & 5.60 & 1.40 \\
\hline $\begin{array}{l}\text { CT8. Utilizaremos internet para crear en común, } \\
\text { remezclar y compartir. }\end{array}$ & 430 & 5.65 & 1.44 \\
\hline $\begin{array}{l}\text { CT9. Internet permitirá crear y ejercer una } \\
\text { inteligencia colectiva. }\end{array}$ & 430 & 5.37 & 1.54 \\
\hline $\begin{array}{l}\text { CT12. Internet será más social, será la web de las } \\
\text { personas. }\end{array}$ & 429 & 4.92 & 1.66 \\
\hline
\end{tabular}

El alumnado imagina una Metodología Docente Futura (ver Tabla 7) basada en un practicum profesional integrado a lo largo de toda la carrera, que utilice recursos educativos abiertos, diversos y objetos de aprendizaje interactivos y coelaborados; que se realicen proyectos reales de acción o investigación en contextos reales, desde un modelo de aprendizaje compartido, distribuido y colaborativo; que integre trabajo y estudio a lo largo de toda la vida; que propicie Entornos Personales de Aprendizaje mediados y use blogs académico-profesionales; y finalmente que se trabaje y evalúe mediante portafolioswikis cooperativos.

Tabla 7

Creencias sobre metodología docente futura

\begin{tabular}{llll}
\hline & N & Media & Desv. típ. \\
\hline $\begin{array}{l}\text { MD1. Queremos realizar proyectos reales de } \\
\text { acción o investigación en contextos reales }\end{array}$ & 419 & 5.84 & 1.39 \\
\hline $\begin{array}{l}\text { MD2. Nos gustaría tener un prácticum profesional } \\
\text { integrado (formación + prácticas) a lo largo de } \\
\text { toda la carrera }\end{array}$ & 428 & 6.05 & 1.39 \\
\hline $\begin{array}{l}\text { MD3. Creemos en la integración trabajo-estudio a } \\
\text { lo largo de toda la vida }\end{array}$ & 428 & 5.79 & 1.41 \\
\hline $\begin{array}{l}\text { MD4. Nos gustaría aprender con recursos } \\
\text { diversos: textos, hipertextos, imágenes, sonidos... }\end{array}$ & 428 & 5.91 & 1.35 \\
\hline $\begin{array}{l}\text { MD5. El aprendizaje será compartido, distribuido, } \\
\text { colaborativo }\end{array}$ & 428 & 5.71 & 1.42 \\
\hline $\begin{array}{l}\text { MD6. Los recursos educativos serán abiertos } \\
\text { MD8. Utilizaremos portafolios-wikis compartidos }\end{array}$ & 426 & 5.73 & 1.38 \\
\hline $\begin{array}{l}\text { MD9. Los profesores tendrán blogs académico- } \\
\text { profesionales }\end{array}$ & 427 & 5.40 & 1.48 \\
\hline $\begin{array}{l}\text { MD10. Utilizaremos objetos de aprendizaje } \\
\text { interactivos y coelaborados }\end{array}$ & 428 & 5.72 & 1.36 \\
\hline $\begin{array}{l}\text { MD11. El profesor propiciará Entornos Personales } \\
\text { de Aprendizaje mediados }\end{array}$ & 426 & 5.79 & 1.36 \\
\hline
\end{tabular}


El alumnado imagina al Profesor del Futuro, por este orden, como un profesor más comunicativo con los alumnos; competente didáctica y tecnológicamente; como tutor, orientador y asesor de personas; como orientador de proyectos personales de formación; como diseñador de objetos de aprendizaje y gestor de contextos de aprendizaje; que elabore y suba videos a la red; como pensador y observador crítico de la realidad; como escritor de sus propias reflexiones y experiencias académicas; un profesor que participe en las redes sociales. En los últimos lugares imaginan al profesor del futuro como un investigador y lector multidisciplinar, así como un docente divergente y generador de conflicto cognitivo. No obstante todas las caracterizaciones, obtienen valores superiores a la media teórica de la escala.

Tabla 8

Creencias sobre los profesores del futuro

\begin{tabular}{|c|c|c|c|}
\hline & $\mathbf{N}$ & Media & Desv. típ. \\
\hline $\begin{array}{l}\text { PF1. El profesor debe ser competente } \\
\text { tecnológicamente (audio, video, PC, internet). }\end{array}$ & 429 & 5.95 & 1.46 \\
\hline $\begin{array}{l}\text { PF2. El profesor debe ser competente } \\
\text { didácticamente con recursos tecnológicos. }\end{array}$ & 427 & 5.99 & 1.43 \\
\hline $\begin{array}{l}\text { PF3. Nos gustaría un profesor que participe en las } \\
\text { redes sociales. }\end{array}$ & 430 & 5.28 & 1.64 \\
\hline $\begin{array}{l}\text { PF4. Nos gustaría un profesor que elabore y suba } \\
\text { videos a la red. }\end{array}$ & 430 & 5.42 & 1.60 \\
\hline $\begin{array}{l}\text { PF5. Nos gustaría un profesor más comunicativo } \\
\text { con los alumnos. }\end{array}$ & 427 & 6.22 & 1.18 \\
\hline $\begin{array}{l}\text { PF7. Ese profesor será un pensador, un } \\
\text { observador crítico de la realidad. }\end{array}$ & 428 & 5.37 & 1.46 \\
\hline $\begin{array}{l}\text { PF8. Ese profesor será un lector multidisciplinar } \\
\text { profundo. }\end{array}$ & 428 & 5.21 & 1.53 \\
\hline $\begin{array}{l}\text { PF9. Ese profesor será investigador } \\
\text { multidisciplinar que publica por interés científico. }\end{array}$ & 427 & 5.22 & 1.48 \\
\hline $\begin{array}{l}\text { PF10. Nos gustaría un docente generador de } \\
\text { conflicto cognitivo, divergente. }\end{array}$ & 428 & 5.21 & 1.56 \\
\hline $\begin{array}{l}\text { PF11. Ese profesor será un escritor de sus propias } \\
\text { reflexiones y experiencias. }\end{array}$ & 428 & 5.36 & 1.48 \\
\hline $\begin{array}{l}\text { PF12. Ese profesor será un gestor de contextos de } \\
\text { aprendizaje. }\end{array}$ & 427 & 5.47 & 1.40 \\
\hline $\begin{array}{l}\text { PF13. Ese profesor será un orientador de } \\
\text { proyectos personales de formación. }\end{array}$ & 428 & 5.55 & 1.43 \\
\hline $\begin{array}{l}\text { PF14. Ese profesor será un diseñador de objetos } \\
\text { de aprendizaje. }\end{array}$ & 428 & 5.53 & 1.45 \\
\hline $\begin{array}{l}\text { PF15. Ese profesor será un tutor, un asesor, un } \\
\text { orientador de personas. }\end{array}$ & 427 & 5.82 & 1.46 \\
\hline
\end{tabular}

El alumnado piensa que en el futuro, por este orden, publicarán en blogs individuales o colaborativos; serán expertos en el procesamiento rápido e intuitivo de información digital multiformato; transformarán la información en producciones digitales; tendrán un rol más constructivo en el aprendizaje, basado en debatir, investigar, criticar y compartir; serán capaces de decidir e intervenir sobre la realidad objeto de su estudio; trabajarán en redes mul- 
tiprofesionales; se organizarán en comunidades virtuales de aprendizaje y serán coproductores de conocimiento, que será un conocimiento pragmático y contextualizado. En último lugar piensan que serán muy creativos.

Tabla 9

Creencias sobre los alumnos futuros

\begin{tabular}{|c|c|c|c|}
\hline & $\mathbf{N}$ & Media & Desv. típ. \\
\hline $\begin{array}{l}\text { AL1. Ejerceremos un rol más constructivo (debatir, } \\
\text { leer, investigar, criticar, escribir, compartir). }\end{array}$ & 426 & 5.42 & 1.56 \\
\hline $\begin{array}{l}\text { AL2. Nos organizaremos en comunidades } \\
\text { virtuales de trabajo. }\end{array}$ & 426 & 5.28 & 1.48 \\
\hline $\begin{array}{l}\text { AL3. Seremos expertos en el procesamiento rápi- } \\
\text { do e intuitivo de información digital multiformato } \\
\text { (texto, audio, imágenes, video). }\end{array}$ & 427 & 5.47 & 1.51 \\
\hline $\begin{array}{l}\text { AL4. Transformaremos la información en } \\
\text { producciones digitales. }\end{array}$ & 427 & 5.43 & 1.41 \\
\hline $\begin{array}{l}\text { AL5. Publicaremos en blogs individuales o } \\
\text { colaborativos. }\end{array}$ & 428 & 5.55 & 1.42 \\
\hline AL6. Trabajaremos en redes multiprofesionales. & 428 & 5.35 & 1.50 \\
\hline $\begin{array}{l}\text { AL7. Seremos capaces de decidir y de intervenir } \\
\text { sobre la realidad en base a la información. }\end{array}$ & 423 & 5.41 & 1.52 \\
\hline $\begin{array}{l}\text { AL8. Seremos muy creativos, fruto de la } \\
\text { hiperestimulación sensorial sufrida en nuestra vida. }\end{array}$ & 423 & 4.95 & 1.69 \\
\hline AL9. Seremos co-productores de conocimiento. & 427 & 5.21 & 1.58 \\
\hline $\begin{array}{l}\text { AL10. Este conocimiento será fundamentalmente } \\
\text { pragmático y muy contextualizado. }\end{array}$ & 426 & 5.04 & 1.55 \\
\hline
\end{tabular}

\section{Relaciones entre Contexto Tecnológico, Metodología Docente, modelo de Profesor y modelo de Alumno}

Pretendemos ahora responder al segundo objetivo de nuestra investigación: confirmar la influencia positiva del contexto tecnológico sobre la metodología didáctica usada (H1) y ésta sobre los modelos de profesor (H2) y de estudiante $(\mathrm{H} 3)$ a partir de las creencias de los alumnos. Ponemos a prueba de esta manera el modelo teórico de la Figura 1 y las tres hipótesis de relaciones incluidas en el mismo mediante un análisis de ecuaciones estructurales en dos fases: en primer lugar con todos los ítems de la escala y en segundo lugar ajustando el modelo con los ítems que mejor definen cada dimensión y la relación entre éstas.

En la primera fase se incluyeron todos los indicadores previstos en la teoría exceptuando los ítems eliminados en el proceso de validación: CT1, CT10, CT11, MD7 y PF6 (ver figura 2). 
Figura 2

Modelo estructural inicial de Educación del Futuro



Dicho modelo consta de cuatro variables latentes y 43 variables observadas. Entre los resultados de este modelo (ver Tabla 10), encontramos cómo los índices de ajuste del modelo $\mathrm{CFI}=0,70$ y de IFI $=0,70$ se sitúan por debajo del 0,90 requerido, debido, en parte, a cargas factoriales insatisfactorias de los ítems por debajo del valor o próximos al valor 0,5 , por lo que dichos ítems fueron eliminados. 
Tabla 10

Índices de ajuste del modelo

\begin{tabular}{|c|c|c|c|}
\hline & Fit Index & $\begin{array}{c}\text { Recommended } \\
\text { Value }\end{array}$ & $\begin{array}{c}\text { Observed } \\
\text { Value }\end{array}$ \\
\hline Absolute fit index & Chi-square/degrees of freedom & $\leq 3.00$ & $5.50 ; \mathrm{p}<.001$ \\
\hline \multirow{3}{*}{ Comparative fit } & IFI (Incremental Fit Index) & $\geq .90$ & .70 \\
\hline & NFI (Normed Fit Index) & $\geq .90$ & .65 \\
\hline & CFI (Comparative Fit Index) & $\geq .90$ & .70 \\
\hline Error of approximation & RMSEA (Root Mean Square Error of Approximation) & $.06 \leq .08$ & .10 \\
\hline Ajuste de muestra & HOELTER .05 & $\geq 200$ & 85 \\
\hline
\end{tabular}

En la segunda fase se incluye el modelo los siguientes ítems (ver Tabla 11).

Tabla 11

Factores e ítems que integran el modelo explicativo

\begin{tabular}{|c|c|}
\hline Factores & Ítems \\
\hline \multirow{3}{*}{$\begin{array}{l}\text { Contexto } \\
\text { Tecnológico }\end{array}$} & CT7. Utilizaremos internet para hacer recomendaciones, opiniones, valoraciones. \\
\hline & CT8. Utilizaremos internet para crear en común, remezclar y compartir. \\
\hline & CT9. Internet permitirá crear y ejercer una inteligencia colectiva. \\
\hline \multirow{4}{*}{$\begin{array}{l}\text { Metodología de } \\
\text { Proyectos } \\
\text { Colaborativos }\end{array}$} & MD4. Nos gustaría aprender con recursos diversos: textos, hipertextos, imágenes, sonidos... \\
\hline & MD5. El aprendizaje será compartido, distribuido, colaborativo. \\
\hline & MD6. Los recursos educativos serán abiertos. \\
\hline & MD10. Utilizaremos objetos de aprendizaje interactivos y coelaborados. \\
\hline \multirow{6}{*}{$\begin{array}{l}\text { Profesor } \\
\text { Orientador- } \\
\text { Sociocrítico }\end{array}$} & PF7. Ese profesor será un pensador, un observador crítico de la realidad. \\
\hline & PF8. Ese profesor será un lector multidisciplinar profundo. \\
\hline & PF12. Ese profesor será un gestor de contextos de aprendizaje. \\
\hline & PF13. Ese profesor será un orientador de proyectos personales de formación. \\
\hline & PF14. Ese profesor será un diseñador de objetos de aprendizaje. \\
\hline & PF15. Ese profesor será un tutor, un asesor, un orientador de personas. \\
\hline \multirow{5}{*}{$\begin{array}{l}\text { Alumno } \\
\text { Constructivo- } \\
\text { Social }\end{array}$} & AL2...Nos organizaremos en comunidades virtuales de trabajo. \\
\hline & $\begin{array}{l}\text { AL3...Seremos expertos en el procesamiento rápido e intuitivo de información digital multiformato } \\
\text { (texto, audio, imágenes, video). }\end{array}$ \\
\hline & AL5...Publicaremos en blogs individuales o colaborativas. \\
\hline & AL6...Trabajaremos en redes multiprofesionales. \\
\hline & AL7...Seremos capaces de decidir y de intervenir sobre la realidad en base a la información. \\
\hline
\end{tabular}

El modelo propuesto se ajusta bien a los datos, como puede observarse en la tabla 12. Los índices de ajuste del modelo reflejan valores aceptables, siendo 
recomendados valores próximos a la unidad, aunque algunos autores admiten un punto de corte más relajado. Por otro lado se hace necesario señalar que cuanto mayor es el tamaño de la muestra, peor son los valores de ajuste (Ruiz, Pardo \& San Martín, 2010). En este sentido, según el criterio HOELTER (.05) indica que N crítica debe ser igual o superior a 200; en el modelo no se satisface esta condición, pero sí cumple rigurosamente con todos los índices establecidos permitiéndonos confirmar el modelo propuesto, ya que existen otros factores que influyen en peores ajustes referente al índice HOELTER y es que los modelos de ecuaciones estructurales admiten pocas variables (Bentler \& Chu, 1985; Lomax, 1982; Ruiz, Pardo \& San Martín, 2010). No obstante, en nuestro caso hemos optado por no eliminar más ítems, dadas las altas puntuaciones significativas a las dimensiones de procedencia, ya que por hallar un mejor valor en el ajuste, al eliminar los ítems se contradicen las premisas teóricas del modelo. Por otro lado, el modelo obtiene un alto nivel explicativo, revelado a través del RMSA. En términos de población se considera un buen ajuste valores entre 0.6 y .08. El número de regresiones significativas que conforman el modelo, así como la ausencia de correlaciones regresiones residuales, permiten la aceptación del modelo, aunque susceptible de réplica con muestras de menor tamaño.

Tabla 12

Índices de ajuste del modelo

\begin{tabular}{llcc}
\hline & \multicolumn{1}{c}{ Fit Index } & $\begin{array}{c}\text { Recommended } \\
\text { Value }\end{array}$ & $\begin{array}{c}\text { Observed } \\
\text { Value }\end{array}$ \\
\hline Absolute fit index & Chi-square/degrees of freedom & $\leq 3.00$ & $3.72 ; \mathrm{p}<.001$ \\
\hline \multirow{2}{*}{ Comparative fit } & IFI (Incremental Fit Index) & $\geq .90$ & .92 \\
\cline { 2 - 4 } & NFI (Normed Fit Index) & $\geq .90$ & .90 \\
\cline { 2 - 4 } & CFI (Comparative Fit Index) & $\geq .90$ & .92 \\
\hline Error of approximation & RMSEA (Root Mean Square Error of Approximation) & $.06 \leq .08$ & .08 \\
\hline Ajuste de muestra & HOELTER .05 & $\geq 200$ & 140 \\
\hline
\end{tabular}

En la figura 3 se muestra cómo el Contexto Tecnológico determina la metodología docente, en este caso a través de Proyectos Colaborativos $(\Omega=.76 ; \mathrm{p}<.001)$; es decir, se espera que los sujetos que han alcanzado mayor puntuación en contexto también manifiesten mayores puntuaciones en la metodología de proyectos. Aunque el contexto tecnológico no tenga una relación causal directa con el resto de factores, si parece ser la causa de que una metodología de proyectos tenga a su vez una relación directa sobre el modelo de profesor orientador $(\Omega=.76 ; \mathrm{p}<.001)$ y sobre el modelo de alumno constructivo-social 
$(ß=.63 ; \mathrm{p}<.001)$. Por lo tanto, una metodología didáctica de proyectos colaborativos, coelaborados, fruto de un aprendizaje compartido y distribuido, se muestra como un fuerte elemento predictor o generador de un modelo de profesor orientador de personas y facilitador de aprendizajes, generador de un modelo de alumnos constructivos, comunitarios y transformadores de la sociedad, y generador también de competencias de reflexión, creación, remezcla, resolución de problemas, gestión de la información y toma de decisiones, competencias que son típicas de los contextos virtuales.

Figura 3

Modelo de ecuaciones estructurales (Educación del Futuro)

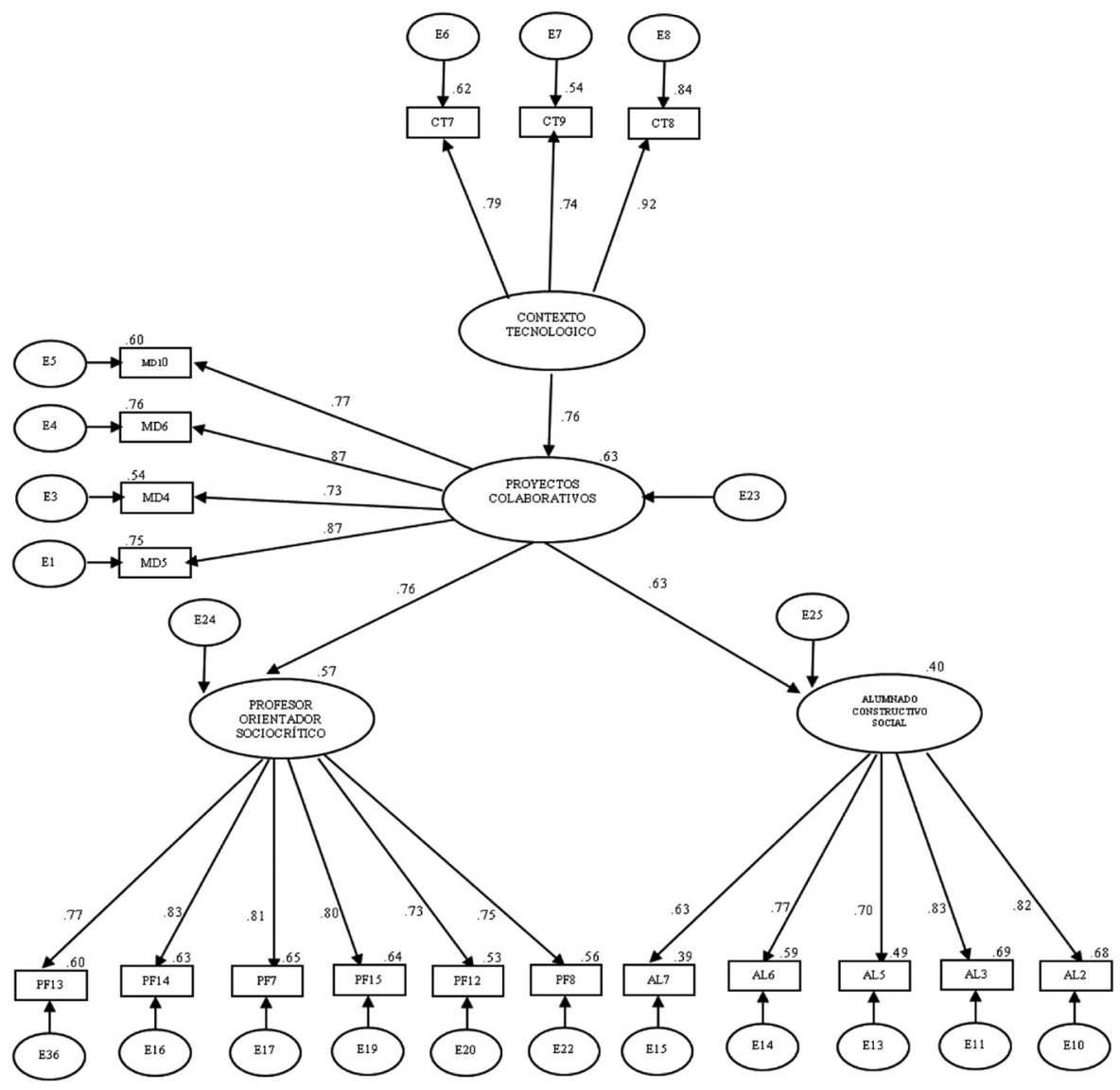




\section{Conclusiones}

Estableceremos las conclusiones en relación a la consecución de los objetivos.

Objetivo 1: Se han descrito las creencias del alumnado sobre la educación del futuro referente al contexto tecnológico, profesores, metodología docente y alumnos.

Objetivo 2: Se ha explorado qué modelo de relaciones entre estas dimensiones subyace en el pensamiento o creencias de los alumnos. En este sentido se ha podido comprobar que el contexto tecnológico es determinante de la metodología docente de proyectos colaborativos y se confirma H1. A su vez la metodología docente de proyectos determina los modelos de profesor orientador y de alumno constructivo-social, y se confirman $\mathrm{H} 2$ y H3. Todo ello configura un modelo lineal-divergente, con forma piramidal, que tiene en su cúspide el determinante contextual tecnológico asociado a una metodología de proyectos colaborativos y que determina a la vez tanto un modelo de profesor orientador sociocrítico como un modelo de alumno constructivo social, modelos de profesor y alumno que no son determinantes entre sí.

Una vez más pensamos que la educación crea contextos de relación humana necesariamente compartidos y socializados. El contexto nunca ha sido neutro, pero quizá ahora, fuertemente vehiculado a través de las tecnologías, la información y el conocimiento, lo es menos. De acuerdo con el estudio realizado por Melgarejo \& Rodríguez (2014), aparecen nuevas herramientas que transforman la concepción de la enseñanza tradicional (inclusión del acceso a Internet, los campus virtuales, las videoconferencias, etc.) emergiendo nuevas metodologías que afectan a docentes y estudiantes. Así el contexto aparece en nuestro estudio como factor determinante primero. Aunque lo que sí nos sorprende como novedad es su capacidad de influencia sobre la metodología docente (Vázquez, 2015), no influye directamente en los actores, profesores y alumnos, generando nuevos modelos de éstos, sino indirectamente a través de la metodología didáctica. Ésta se convierte en verdadera fuente o pilar del nuevo modelo de educación futura. De ahí que aparezcan cambios significativos en el proceso educativo: mayor protagonismo del estudiante, desarrollo de competencias, nuevos conocimientos y habilidades, adquisición de herramientas, incorporación de las TIC, comunicación interpersonal y trabajo en equipo, tal como señala (Riera, 2016). Es la metodología didáctica, los nuevos modos de enseñar, singularizada en el modelo de proyectos colaborativos de investigación e intervención, el determinante del cambio en los modelos de profesor y de alumno, así como de las competencias a desarrollar por ciudadanos duales (reales y virtuales). Por tanto tenemos que reconocer que es la metodología basada en proyectos la que está forzando 
a los profesores a adoptar un modelo docente basado en el asesoramiento, en la mediación, la tutoría, la colaboración, la investigación, la creación y la crítica, profesores más centrados en el aprendizaje que en la docencia (López, González \& León, 2015). De igual manera, de acuerdo Hernández (2017), comprobamos que son los cambios metodológicos los que están exigiendo un nuevo tipo de alumno. Siempre decimos que los alumnos hacen lo que les proponemos los profesores con nuestro método de trabajo. Un alumno que lee, investiga, debate, critica, escribe y comparte sobre todo en comunidades virtuales y redes sociales, experto en procesamiento de información digital, capaz de transformarla y reutilizarla, consciente de su identidad en la red sobre la que vuelca producciones propias, y capaz de tomar decisiones sobre sí mismo y la realidad (Suárez, Pérez, Boza \& García, 2012).

Como limitaciones del estudio señalamos sobre todo el constructo teórico, remezcla entre realidad y deseo, con cierta visión prospectiva. Esto generó ciertos desajustes en el diseño del propio instrumento, algo que no es una limitación sino un logro del trabajo, dado que se ha resuelto satisfactoriamente en los procesos de validación del instrumento. También señalamos como limitación el uso de una muestra incidental de voluntarios circunscrita a una sola universidad, a pesar de lo cual consideramos que tiene un tamaño suficiente y representativo para un estudio exploratorio en el que al menos se han tenido en cuenta las cuotas correspondientes a sexo y titulación.

Como prospectiva señalamos la necesidad de seguir explorando este tema. Si no prevemos el futuro, la educación siempre irá detrás de la sociedad en vez ser vanguardia de la misma. También indicamos la importancia de recoger datos en otros contextos, universitarios y de secundaria, ampliar las muestras y cuidar el muestreo. Por otro lado este trabajo pone de manifiesto la necesidad de que el alumno sea verdadero protagonista de la educación, modelo validado. Ello requiere que los profesores demos un paso atrás y nos atrevamos a permitir que nuestros alumnos sean verdaderos gestores de sus aprendizajes.

\section{Referencias}

Adams, S., Cummins, M., Davis, A., Freeman, A., Hall, C., \& Ananthanarayanan, V. (2017). NMC Horizon Report: 2017 Higher Education Edition. Austin, Texas: The New Media Consortium.

Bentler, P. M. (1985). Theory and implementation of EQS: A structural equations program. Los Ángeles: BMDP Statistical Software.

Boza, A. \& Conde, S. (2017). La educación del futuro: perspectiva del alumnado. Validación de una escala. En revisión. 
Castaño, C., Maiz, I. \& Garay,U. (2015). Redes sociales y aprendizaje cooperativo en un моос. Revista Complutense de Educación, 26, 119-139. DOI: http:/ / dx.doi. org/10.5209/rev_RCED.2015.v26.46328

Díaz, I., Cebrián, S. \& Fuster, I. (2016). Las competencias en TIC de estudiantes universitarios del ámbito de la educación y su relación con las estrategias de aprendizaje. RELIEVE, 22 (1). DOI: http:/ / dx.doi.org/0.7203/relieve.22.1.8159

García, A. \& Tejedor, F. J. (en prensa). Percepción de los estudiantes sobre el valor de las TIC en sus estrategias de aprendizaje y su relación con el rendimiento. Educación XXI. Recuperado de http://revistas.uned.es/index.php/educacionXX1/article/download/13447/13537

Hernández, R. (2017). Impacto de las TIC en la educación: Retos y Perspectivas. Propósitos y Representaciones, 1 (5), 325-347. DoI: http://dx.doi.org/10.20511/ pyr2017.v5n1.149

Herrera, A. (2015). Una mirada reflexiva sobre las tic en Educación Superior. Revista Electrónica de Investigación Educativa. 17 (1) 1-4.

Hien, M.; Chang, Z. \& Nguyet, A. (2017). The effect of blended learning on student performance at course-level in higher education: A meta-analysis. Studies in Educational Evaluation, 53, 17-28. Dor: http:/ / dx.doi.org/10.1016/j.stueduc.2017.01.002

Liesa, M., Vázquez, S., \& Lloret, J. (2016). Identificación de las fortalezas y debilidades de la competencia digital en el uso de aplicaciones de internet del alumno de primer curso del Grado de Magisterio. Revista complutense de educación, 2 (27), 845-862. DOI: http://dx.doi.org/10.5209/rev_RCED.2016.v27. n2.48409

Lomax, R. G. (1982). A guide to LISREL-type structural equation modeling. Behaviour Research Methods and Instrumentation, 14, 1-8.

López, A. B., González, I. \& de León, C. (2015). Exploratory factor analysis to construct a model of university teaching evaluation indicators, Culture and Education, 27, 337-371. DoI: http:/ / dx.doi.org/10.1080/11356405.2015.1035546

Manrique, K. A. (2015). La web 2.0 y sus servicios como herramientas en el entorno educativo del siglo xxI. Revista digital universitaria, 9 (16), 1-13. Recuperado de http:/ / www.revista.unam.mx/vol.16/num9/art76/

Melgarejo, I. \& Rodríguez, M. (2014). El nuevo entorno educativo de Bolonia: ágoras transformadas por el esquema Tecno-Holista. Historia y Comunicación Social, 19, 797-812. Recuperado de http:/ / revistas.ucm.es/index.php/HICS/ article/view/45003/42374

NMC (2017). Horizon Report, Higher Education Edition. Recuperado de: http:/ /academedia.org/2017_NMC_horizon.pdf

Pérez, M. S.; Ortiz, M. G. \& Flores, M. M. (2015). Redes sociales en Educación y propuestas metodológicas para su estudio. Ciencia, Docencia y Tecnología, 26 (50), 188-206. Recuperado de http:/ / www.pcient.uner.edu.ar/index.php/ cdyt/article/view/53/62

Riera, J. (2016). Educational innovation at the university and the new role of professors. Revista de Psicologia, Ciències de l'Educació i de l'Esport, 34 (1), 23-31. 
Ruiz, M. A., Pardo, A. \& San Martín, R. (2010). Modelos de ecuaciones estructurales. Papeles del Psicólogo, 31, 34-45. Recuperado de http:/ / www.redalyc.org/ articulo.oa? id $=77812441004$

Suárez, J. M., Pérez, A., Boza, A. \& García, A. (2012). Educación 2.0. Horizontes de la innovación en educación. En Jiménez, C.; García, J. L., Álvarez, B. \& Quintanal, J. Investigación y educación en un mundo en red. Madrid: McGrawHill.

Trujillo, J. M., Aznar, I. \& Cáceres, M. P. (2015). Análisis del uso e integración de redes sociales colaborativas en comunidades de aprendizaje de la Universidad de Granada (España) y John Moores de Liverpool (Reino Unido). Revista Complutense de Educación, 26, 289-311. Dor: http://dx.doi.org/10.5209/ rev_RCED.2015.v26.46380.

Vázquez, J. A. (2015). Nuevos escenarios y tendencias universitarias. Revista de Investigación Educativa, 33 (1), 13-26. DoI: http://dx.doi.org/10.6018/ rie.33.1.211501 
